\title{
Ritual as a method of social memory content transfer
}

\author{
Anna N. Utkinaa $^{1, a}$, Veronika E. Mironova ${ }^{1}$, Olga T. Loiko ${ }^{1}$ and Alexandr E. Volkov ${ }^{1}$ \\ ${ }^{1}$ National Research Tomsk Polytechnic University, 634050 Lenin Avenue, 30, Tomsk, Russia
}

\begin{abstract}
The paper deals with a ritual as a method of social memory content transfer. To reveal dialectics of ritual phenomenon formation and development, hermeneutical, dialectical and general scientific approaches as well as analysis and synthesis are applied. Social memory is considered as a complex of essential information for a society rooted in a social medium mentality and transferred from one generation to another. In terms of analyzed theoretical approaches to ritual and social memory the authors conclude that a ritual is capable of transferring social memory from one social stratum to another retaining its content. By means of a ritual, the process of conversation between different individuals is implemented, and the unity of memories is formed. Ritual instability allows changing its form dialectically retaining its content unvaried. Ritual preserves, presents and keeps its content current taking into account changing forms of manifestation that define the dynamics of society development. Reflecting the inner content of a social memory ritual contributes to its literal perception in the modern world and, as a consequence, to the reduction of social conscience manipulation. The development of society is in great necessity in such methods of social memory transfer that are capable of responding to social changes retaining important information for society ungarbled. The authors consider a ritual as one of such methods.
\end{abstract}

\section{Introduction}

The importance of the subject studied in the given article is based on dialectic of present social development. On the one hand, in modern society the solution of generation continuity and the loss of culpability relatively the entire social medium occur. At the same time, the interest to the social memory study rises; within the phenomenon it is possible to actualize, transform and reconstruct the perception of the past defying identity of both social medium and personality.

Social memory is a phenomenon supporting group identities. In this regard, a modern person requires means for literal perception of social memory, for its preservation and transfer to the future generation. Humankind accumulated a lot of verbal and nonverbal ways of social memory transfer, among which a ritual is considered to be of great importance. The article contains the analyses of the ritual as a phenomenon capable of bringing the innermost content of social memory. Understanding the meaning and content of the social memory phenomenon is necessary to a person living in the modern multicultural world. Participation in community ritual action contributes to personal identification with a certain social group. As a result, a person obtains confidence in the future and the meaning of her or his real existence in the course of social memory. The process of globalization leads to ritual unification while modern society is becoming more ritualized. People make attempts to apply information about the past in order to explain behavioral rituals that regulate social relations. Therefore, to preserve a sociocultural integrity of the society it is necessary to reveal socio-philosophical underpinnings that will contribute to more thorough transfer of the social memory content. Mnemosyne, thought of as the mother of nine muses in ancient philosophy, once said to her children: „There are no brains without memory“"[1].

\section{Theoretical frameworks}

Memory problematics has been studied throughout the whole period of philosophical thought existence. Social memory obtained the status of an ontological phenomenon with the appearance of sociology. At the end of the $19^{\text {th }}$ century the concept of "collective" and "social memory" made a contribution to the development of conceptual studies in the given sphere in the $20^{\text {th }}$ century [2]. Taking into consideration the existing investigations of social memory, its separate aspects are revealed, various approaches and ways of its study are applied.

\footnotetext{
${ }^{\mathrm{a}}$ Corresponding author: an_utkina@mail.ru
} 
The idea of social memory transfer by means of cultural facilities belongs to art historian A. Warburg who explained works of art as "cultural descriptive symbols" created in "certain community" and expressing their cultural identity [3]. Sociological research of memory was carried out by M. Halbwachs, who theoretically explained the existence of both individual and collective types of memory. J. Assman contributed the idea of the memory informative content that is defined by the social and cultural framework [4]. Contemporary scientists such as S. Klein and S. Nichols wrote: "Memory is at the heart of the way most people think about personal identity" [5]. Examining memories, Van Dyke revealed them not as being ready-made reflections of the past, but as eclectic and selective reconstructions. He believes social memory to be an active and ongoing process because people remember or forget the past according to the needs of the present [6]. Modern science denotes cultural and social roots of biographic memory. The work of Andrea Smorti and Chiara Fioretti is devoted to the problematics under consideration. [7]. The connection between social memory and ritual performance was studied by contemporary British archaeologist R. Peterson, who writes about archaeological evidence for the mechanisms by which group memory is transferred [8].

Ritual conceptual studies are presented in works of E. Durkheim, C. Jung, C. Levi-Strauss, E. Leach, M. Mauss, B. Malinowski, V. Terner, R. Collins, J. Lotman, etc.

E. Durkheim analyzed ritual functions as system organization. C. Jung proved that a ritual exists in unconscious human memory. In works of C. LeviStrauss and E. Leach a ritual is analyzed as a means of nonverbal communication, and the scientists revealed its communicative function which is considered to be basic for the formation of all the other functions of a ritual. The analysis of nonverbal information transfer in terms of a ritual carried out by E. Leach, highlights the way a ritual transfers the message. The concept of a ritual presented in works of M. Mauss, B. Malinowski, J. Lotman is connected with solution of an important social problem by means of the ritual. The key function of a ritual is memory organization. V. Turner studied the nature of the ritual and proved that a ritual is of great importance in preserving social relations [9]. $\mathrm{R}$. Collins created the theory of interactive rituals and identified six essential parts of the ritual.

The development of modern mass media caused the formation of imaginary space. Investigating the given space the German scientist, S. Ismer, revealed that an individual needs a ritual to realize her or his identity with this space. According to $\mathrm{S}$. Ismer a ritual provides emotional experience of the imagined community. Moreover, it analyses its emotional content. For example, during the international matches broadcast the nation may compare itself with the representatives of another identity [10].

\section{Ritual in social memory context}

As far as social memory is a general phenomenon and contains all kinds of the memory, the ritual analysis in its context allows revealing its nature to the full extent. To achieve the objective, it is necessary to define the phenomena of ritual and social memory.

"Social memory is a complex of essential social information contained in social mentality and transferred from one generation to another" [11].

"Ritual is a way of existence transferring from one generation and social stratum to another allowing to deliver the essential content of social memory in a constantly changing state" [11].

One of the first scientists studying collective memory was M. Halbwachs. In his work "Social memory framework" he presents theoretical underpinning of both individual and collective memory existence. According to M. Halbwachs, despite their close interrelation, collective memory is capable of turning round individual memory, however, it does not intermingle with them following its own laws. M. Halbwachs devotes the whole chapter of the given book to mechanisms of memory formation and reconstruction of the past. He made the statement that our memory is not reproduction of the past experience but its reconstruction [12]. On the basis of the given statement it is possible to assume that rituals of memory allow the society or a social group to implement such reconstruction. According to $\mathrm{M}$. Halbwachs, it is necessary to understand the viewpoint of the group transferred from the individual self, as well as to see how a certain fact becomes memorable while entering the range of national interests. We memorize the event form our childhood when we realize others feel excited about it [12]. Thus the position of M. Halbwachs allows considering a ritual as a mechanism to create a specific emotional atmosphere for memorizing the event and reconstruction of the past in memory of an individual. On the basis of the research conducted by $\mathrm{M}$. Halbwachs, we can draw two conclusions: 1) The role of a ritual in social memory is not only in recording, but also in transmission of essential social information. 2) A ritual is capable of creating specific atmosphere for memorizing, and participation in a ritual act allows reconstructing the past.

A. Warburg, the art historian suggested the idea of social memory, spreading through the community of remembering people, wherein social memory is considered to be not only the entire fund of images and gestures that East and West possess, but the way they manage cultural heritage [3].

As participants of a memory ritual become a remembering community, it provides us with a basis for the study of a ritual as a means of social memory content transfer.

The idea of the informative memory content, which is defined by the social and cultural framework, was suggested by J. Assman. He distinguished four spheres of memory measurement: 1) mimetic memory, 2) objective memory, 3) communicative memory, 4) 
cultural memory forming specific space where the previous three memory types combine. When mimetic skills acquire semantic meaning apart from their target value, they no longer a part of a memory mimetic activity sphere [4]. However, according to J. Assman, mimetic skills acquire semantic meaning when they obtain the status of a ritual. He refers a ritual to cultural memory and identifies it as the form of transfer and revival of cultural meaning. To understand a ritual as existence of social memory, the attitude of J. Assman to the feast is of great importance. The evocation of demonstrating past is considered as one of the key feast functions. He understands a valid appeal to the past as an identity of a remembering group. The viewpoint of Y.Assman, expressed by the idea that socially essential events, such as holidays, are reflected in the rituals of the highest level, allows considering a ritual as a way of social memory transfer. The performance of the ritual, devoted to a certain event important to a social group, makes it possible to inscribe the given event in the memory. Furthermore, the rituals of recollection fulfill a retrospective function newly reproducing this event in the content of social memory. On the basis of this fact it is possible to conclude that a ritual is characterized by occasionality which is its distinctive feature.

Thus, social memory is a common sociophilosophical phenomenon in its content and, therefore, it fixes essential characteristics of social existence. "Social memory appears when a person starts to realize herself/himself not only as a member of a tribal, clan, or craft organization, but also as a free subject who is able to define value and meaningful goals herself/himself' [13].

\section{A ritual as a means of social memory transfer}

The nature of a ritual is a complex phenomenon; moreover, the ritual phenomenon is studied in various scientific concepts. C. Jung explained that a ritual draws attention and is of interest to people making it possible to obtain individual experience within the group. It preserves the opportunity to stay a selfidentical personality [14]. Jung revealed that a ritual contributes to individual identification with a certain social group [14]. On the given basis it is possible to assume that participation of an individual in a ritual act through involvement in the situation allows identifying oneself with a social group and join in the social memory of this group. C. Jung proved that a ritual is used for transformation; it becomes specific technology that an individual follows [14]. C. Jung explains a ritual as transformation technology expressed in imitation of successive events. As an example he presents various rituals, both western and eastern. They are different in a form, however, their common goal is to achieve transformation of an individual [14].

Thus, the scientific viewpoint of C. Jung proved that a ritual has a labile form, however, it preserves its content. Therefore, special attention should be paid not to the form of the ritual, but to its contents function.

A ritual forms liability with its essence preserved, which is corroborated by the research of M. Mauss. Studying formal ritual texts, M. Mauss came to the conclusion that they are created according to the common plan presenting the basic ritual that changes due to various demands [15]. M. Mauss points out that the key content and meaning of a ritual remain the same, only its form changes. Ritual changes, determined by society, demand not to deform its meaning. According to M. Mauss, the concept of the sacral is a fundamental notion of a ritual, while the sacral is the result of collective activity, i. e. a social concept [15]. On the basis of sacral texts under study, M. Mauss defined that a ritual existed long before its description. It proves the fact that a ritual is a preliterate form of social memory. M. Mauss studied the prayer as a verbal ritual because it is an accepted course of action. The scientific viewpoint of M. Mauss shows that the prayer is social both in the form and in the content. It does not exist outside a ritual system. According to M. Mauss a ritual acquires explanation and justification when its basic meaning is revealed. First of all, rituals present movement of the human soul, not the body. They are enriched with elements of mental activity, such as feelings and ideas [15]. M. Mauss put forward an assumption that revelation of one primitive verbal rituals type and defining universal qualities for various communities are possible because we study the phenomenon necessary for all social group of the given kind.

The analysis of M. Mauss's research makes it possible to conclude that a ritual system is essential for society existence that is impossible without social memory.

In works of C. Levi-Strauss and E. Leach a communicative function of a ritual is defined as main on the basis of which all the rest functions were formed. Addressees and addressants of messages participating in ritual are the same people. As E. Leach states, they accumulate communicative experience together through various sensory canals simultaneously and act in accordance with consistent succession of metaphorical events within a certain territory [16]. E. Leach analyzed the process of nonverbal information transfer by means of a ritual and revealed the way a ritual is capable of information transfer. As the message transferred by a ritual has both addressers and addressees, it is possible to state that a ritual is characterized by dialogueness and, therefore, has feedback. Thus, E. Leach was one of the first researchers who presented the ritual dialogueness.

On the basis of the given analysis it is possible to come to a conclusion that by means of nonverbal communicative canals a ritual is capable of transfer the content of social memory. Further, the message nonverbality contributes to a better perception of a social memory content as linguistic means make the process of understanding the communicative message more complicated. In a similar way at the 
communicative level a ritual forms an identity of understanding the other one.

R. Collins, the founder of the interactive rituals theory proved that participants of a ritual act feel like group members having mutual moral duties. In the ritual a temporary integration of all participants into general reality occurs [17]. According to R. Collins, a ritual consists of several essential parts, one of which is emotional energy; for its renewal people participate in a ritual act time and again. Studying interactive rituals of intellectuals, Collins revealed the role of ritual acts in transfer of the scientific memory content that is a certain segment of social memory.

Thus, the interactive rituals theory of R. Collins proves dialectical interrelation of a ritual with social memory. The application of the given theory to identification of these phenomena interconnection also reveals that emotional atmosphere that appears in the process of any ritual act, contributes to both memorizing and recollection. Therefore, reviving its rituals, the society preserves its memory as well as transfers its content between generations.

J. M. Lotman, the Russian scientist, emphasizes a specific character of a ritual phenomenon: 'memory organization plays the key role in the ritual, which is a mechanism of individual inclusion to the collective memory" [18, p. 6]. J. M. Lotman explains that a ritual is a means of collective experience memorizing with its following transfer between generations that proves the role of a ritual in collective memory transfer. The ritual definition of J. M. Lotman as a mechanism of collective memory inclusion allows considering a ritual as a mechanism of social memory inclusion. According to M. J. Lotman, as a ritual contributes to memorizing of essential information with its following transfer, on the basis of the given fact it is possible to develop the idea of a ritual as a mechanism of social memory transfer. The perception of the technologies that perform complicated ritual procedures with the deepest symbolic content is capable of a better presentation of the processes of social memory content transfer. A ritual due to its practical nature as a mechanism of social memory content transfer makes a big difference. Dialectics of a ritual is reflected in its changing forms while interdisciplinary analyses of a ritual reveal its nature as a way of social memory existence.

\section{Conclusion}

Thus, the basic concepts of a ritual and the social memory study prove that by means of a ritual an individual identification with a certain social group and preserving temporal unity of dynamically developing society occur. Due to its dialectical nature, a ritual is capable of social memory essence reflection. Ritual instability allows changing its form dialectically, retaining its content unvaried. A ritual preserves, presents and keeps its content current taking into account changing forms of manifestation that define the dynamics of society development. A ritual latently preserves the content of social memory and transmits its fundamental nature in a more important form for the given social medium. A ritual is interlocutory as it is capable of fulfilling the process of social communication between different individuals for definite consensus building. It contributes to existence within the social memory for a given society. Occasionality of the ritual serves to team or society building and benefits from its involvement in an important event in the content of social memory. By means of ritual occasionality both inner and outer social memory content is transferred. By means of nonverbal and verbal communication, a ritual presents an important event for society. Besides, the given discursiveness of the ritual is socially oriented taking into account the status of ritual practice participants and a social norm. It contributes to a complete rendering of the social memory content. The understanding of the meaning and content of a social memory phenomenon is necessary for individuals living in the modern multicultural world. Participation in a collective ritual act contributes to identification of a personality with a certain social group. As a result, a person obtains confidence in her or his future and meaning of her or his real existence within the framework of social memory. The ritual transfers the social memory content from one social stratum to another that plays an important role in formation of a unique sociocultural sphere. A relevant rendering of the inner social memory content is essential for reduction of social conscience manipulation. Therefore, the further study of a ritual and social memory problems as dialectically interconnected phenomena will contribute to relevant transfer and perception of the social memory content, identification of an individual in modern conditions of globalization and development of the mutual understanding policy in society.

\section{References}

1. F. M. Voltaire, A case with Memory (M.: Klassiki i sowremenniki, 1995)

2. E. Brian, M. Jaisson, R. Mukherjee, I. S. J., March-June 203/204, 8 (2012)

3. A. Warburg, Und der Antisemitismus. Kulturwissenschaft als Geistespolitik (Beck Verlag, 1997)

4. J. Assmann, Das kulturelle Gedächtnis: Schrift, Erinnerung und politische Identität in früher Hochkulturen (München: Beck, 2000)

5. S. Klein \& S. Nichols, Memory and the Sense of Personal Identity (2012)

6. Van Dyke, R.M., \& S. E. Archaeologies of memory. (Alcock, 2003)

7. A. Smorti, Ch. Fioretti, I.P. \& B. S., 3, (2015)

8. R. Peterson, J. S. A, 13(2), 266-283 (2013)

9. V. Turner, Simvol i ritual (M.: Nauka, 1983)

10. S. Ismer, O. Z. S, 39, 131-151 (2014)

11. A. N.Utkina, Ritual in a social memory: monograph (Tomsk, 2015) 
12. M. Halbwachs, On Collective memory (The Unevercity of Chicago Press, Ltd., Chicago and London, 1992)

13. O. Loyko, MEJSR, 21(1), 282-285 (2014)

14. C. Jung, Dusha I mif: shest arhetipov: per s angl (K.: Gosudarstvennaya biblioteka Ukrainy dlya yunoshestva, 1996)

15. M. Mauss, URL: http://ib.unidubna.ru/search/files

16. E. Leach, Culture and communication: the logic by which symbols are connected. An introduction to the use of structuralist analysis in social anthropology (Cambridge University press, 1976)

17. R. Collins, The Sociology of Philosophies: $A$ Global theory of Intellectual Change (Cambridge, Mass.: The Belknap Press of Harvard university Press, 1998)

18. Y.M. Lotman, $O$ dinamike kultury (Uchen. Zap. Tart. Un-t., 1984) 